\title{
"La violencia genéticamente patriarcal no reconoce fronteras de clases, de lugares, de espacios"
}

ENTREVISTA

\section{Por Bárbara Bilbao}

Universidad Nacional de La Plata y Universidad Nacional Quilmes, Consejo Nacional de Investigaciones Científicas y Técnicas, Argentina.

barbarabilbao@gmail.com

Recibido: julio del 2016

Aceptado: agosto del 2016

\section{Entrevista a}

Dora Barrancos es Licenciada en Sociología por la Facultad de Filosofía y Letras de la Universidad de Buenos Aires (UBA); allí obtuvo el Diploma de Honor. Es Mestre em Educaçao, otorgado por la Faculdade de Educaçao, Universidade Federal de Minas Gerais, Belo Horizonte, Brasil; y Doctora en Historia, por el Instituto de Filosofía e Ciencias Humanas de la Universidade Estadual de Campinas, Brasil. Investigadora Principal del Consejo Nacional de Investigaciones Científicas y Técnicas (CONICET) y, Directora del mismo establecimiento en representación a las disciplinas de Ciencias Sociales y Humanas. Profesora Consulta de la Facultad de Ciencias Sociales, de la UBA. Fue directora del Instituto Interdisciplinario de Estudios de Género, de la Facultad de Filosofía y Letras, de la UBA (2000-2010). Ex Directora de la Maestría y del Doctorado en Ciencias Sociales y Humanidades de la Universidad Nacional de Quilmes (UNQ). Entre toda su trayectoria académica, integra y dirige la comisión para el armado del Protocolo contra la Violencia de Género en la UNQ. (Ver video)

Bilbao: Dora, ¿cómo narrarías, describirías tus intereses investigativos?

Barrancos: Bueno, dos vertientes. Una bien interesante, que es lo que investigo. Hace casi un cuarto de siglo que me he dedicado a mirar, observar, analizar la cuestión de género, la condición femenina en nuestra historia. Pero como soy Socióloga, también estoy mirando el presente. Voy al pasado con preguntas del presente. Es claro que todo lo que hago converge en el sentido de aumentar la visibilidad, el reconocimiento y la dignificación de esos sujetos que analizo. Las significaciones del pasado en el presente. 
De las congéneres, de las opresiones, de las limitaciones tremendas de la condición femenina para seguir el reglamento patriarcal. La naturalización de que el patriarcado ha forjado en torno a que es inexorable y que no puede cambiarse. Eso me interesa profundamente. Tengo un repertorio amplio. No me movía de mediados de siglo pasado, pero ahora sí. He escrito sobre peronismo, sobre el anti-feminismo de Evita. He saltado la tranquera y me he venido más acá en relación a las crisis y las mujeres. Como un cuadro es verdaderamente crítico. Cuando la crisis es societal, de envergadura es inexorable la sobre-presencia femenina. Todo el movimiento de piqueteras muestra que hay un lugar de liderazgo por parte de las mujeres, de salirse del lugar de género. Las mujeres se desapegan de sus mandatos, ocupan calles, son capaces de muchísimas cosas que no se corresponden con el sexo, podríamos decir. Todavía es objeto de mucha reflexión. "Las aguas vuelven al nivel": se siente, se ve que hay una vuelta a la retaguardia, como un campo de la contradicción fuerte del mandato de género. Muchas mujeres piqueteras hoy ya no están en escena, y muchas se han resignificado. Pensemos en Milagro, encarcelada. Hay un incitante para pensar nuevamente en esto que te digo. Últimamente me he dedicado fuertemente a un trabajo que ya había elaborado en referencia a la materia cultural del liberalismo entre Argentina y Uruguay y la cuestión de género cruzando. Que permite diferenciar ambas posiciones liberales que son muy contrastantes. Es un trabajo publicado. Eso me desafió. Una busca el punto desafiante. Y también me motivó muchísimo (el conocimiento va del conocer al desconocer) investigar la cuestión de las aviadoras argentinas. Empezando por la historia de las francesas. Aquí, en la Argentina, hay una matriculación muy alta de aviadoras durante los 50 y 60 .

Bilbao: Qué interesante, ¿pudo escuchar sobre el caso en el que dos personas se bajaron de un avión porque era piloteado por dos mujeres?

Barrancos: Si, en ese caso, habría que iniciar una denuncia en términos judiciales por altísima capacidad discriminante. Allí sí que hay capacidad discriminante. Porque tuvieron tiempo de elaborarlo. Primero no lo podía creer pero parece que fue así. Fue en American Airlains. Sí, recuerdo otro caso en el que dos pilotas venían de Salta y la reacción fue al contrario, las aplaudieron y felicitaron y, en cuanto llegaron a Buenos Aires, las entrevistaron y dijeron: "bueno, fuimos y vinimos y no rompimos nada". La verdad que es lamentable que sigan ocurriendo cuestiones como éstas.

Bilbao: ¿Eso puede ser denunciado? 
Barrancos: Por supuesto. Si las pilotas hubieran sido argentinas acá tienen legislación para protegerse, en ese caso eran norteamericanas. Durante los '60 hubo una mujer que enseñaba a aterrizar con paracaídas. Era instructora de paracaidismo. Las primeras aviadoras que yo tomo son dos que mueren trágicamente. Los aviones eran muy precarios en ese momento, ante mínimas cuestiones de impericia ocasionaban tragedias. Una trató de hacer maniobras, tal vez, criminales. La otra quería pilotear, era muy experta. En esa ocasión, quiso hacer un homenaje a cinco pilotas uruguayas. Insistió, le prepararon el avión, estimo que lo prepararon mal o intentó hacer un giro que no logró retomar altura y se estalló trágicamente. Me sorprendí sobre mi ignorancia en esos temas. Hay trabajos que son más burocráticos y otros que no. Donde aparece la vibración libidinal. Es muy acuciante. Todo tiene un límite también. Voy a tratar de publicar algo -a través de una editorial que tengo apalabrada- sobre algunas mujeres y sus contribuciones laborales y profesionales (comunicólogas, historiadoras amateurs), desde el siglo XIX hasta un poco adentrados los setenta. Es un trabajo de síntesis sobre aquellas mujeres que no llegaron a "los reflectores", a visibilizarse; sobre qué ha pasado con las amateurs y las profesionales.

Bilbao: Esperaremos la salida de ese libro. ¿Y volviendo a la otra vertiente en tanto a la práctica de la investigación que comentabas?

Barrancos: Ahora viene la parte más administrativa de la vida investigativa. No tenía planeado ser Directora de CONICET. Vinieron a verme algunas gentes a decirme: "Dora es el momento y la oportunidad". Estaba muy ocupada en la cuestión de la investigación. Y bueno surgió, vino a verme gente del interior a decirme que era la candidata. Así ocurrió y dijimos: "bueno vamos, pensemos el plan". Surgió el plan que puse en consideración de muchos colegas. Fue una decisión muy grande. Como esto es un acto muy felizmente democrático, se votó y bueno aquí estoy. Era una oportunidad interesante para hacer cambios. No todos los que una puede desear, pero fue entusiasmante hacer modificaciones normativas con relación a las mujeres. Por ejemplo, el automático cambio que posibilita la ampliación del tiempo de beca por la cantidad de hijos. Ahora bien, el modo de plantearlos era decisivo. El punto era insistir en que eso no era el planteo de un sector, sino de la Constitución Argentina. No hay igualdad, eso lo sabemos, porque cuando una mujer tiene un hijo/a tiene que ocuparse por "mandato" y eso no se ha modificado socialmente. Otro ejemplo es el aplazamiento del informe reglamentario en el 
año de "alumbramiento". Se pide posponer el informe por un año. Tengo que hacer una investigación a ver si todo el mundo está con este tema. Es un derecho, no es lo mismo que el apartamiento por gestación y parto. Es más que un derecho. Tienen que retirarse 90 días que es muy poco, ¿No? En varios lugares del Estado se ha cambiado y en muchas paritarias se ha cambiado para 100 días. Muchos países han sostenido por 6 meses. Algunas universidades lo han hecho, Córdoba por ejemplo. Eso lo tendremos en la apertura de todas las relaciones que tenemos que pactar: el estatuto nuevo, en el que cambiaremos las edades, demografía. Logramos que se incrementara la "sensibilidad por la inequidad de género". De modo que hoy es automático. La extensión es automática: madre de un niño hasta 36, madre de dos hasta 37, madre de 3, 38. Esto ayuda a mejorar y dar garantías de inclusión social. Yo quería becas de orden social que fueron muy discutidas. Determinadas becas que iban destinadas a personas que se habían atrasado en el plano formativo porque habían tenido que trabajar o tenían familias en condición de vulnerabilidad, de pobreza. Eso fue todo un debate. Finalmente lo que ampliamos fueron las edades: a 32 la doctoral y a 35 la post-doctoral. Es una ampliación muy interesante, que hemos hecho bastante bien y tiene reconocimiento internacional. En nuestro sistema hay sobre-representación de mujeres. Las mujeres son mas en el sistema científico argentino que además, es el mejor rankeado. La participación de las mujeres en ciencia es del $52 \%$. Nos debemos un cuadro interpretativo sobre por qué las mujeres han estado tan bien acogidas en las Ciencias Biológicas y no han aumentado tan considerablemente en las Ciencias Sociales. Yo tengo algunas hipótesis pero aún no es el momento de presentarlas. En cuanto a los cambios fue bastante iluminador. Este tipo de medidas destella algún tipo de proyección y la gente de golpe se da cuenta de que hay discriminación de género. Las científicas tardan en caer en que existe tal discriminación, lo colocan en un lugar individual. Como una coraza, para no examinar las situaciones abruptas y negativas que se han tenido.

Bilbao: ¿Cómo se inscribe esto respecto de lo que se trabaja como violencia institucional?

Barrancos: Toda discriminación es violencia. Esa violencia puede ser reconocida como tal, de hecho eso es lo que está ocurriendo. La violencia que acarrea las otras violencias. En la experiencia de CONICET, que es tan amplio y disperso, llama la atención la cantidad de tensiones que existen -que algunas se manifiestan de manera abrupta y otras están como adormecidas. Hemos demorado mucho pero a partir del mes que viene 
(Septiembre) consagraremos lo que es nuestro Protocolo contra la Violencia de Género en las instituciones. Prevenir las violencias en las instituciones. Para frenar la violencia intra-institucional. La violencia incluso en las casas debería ser tema a trabajar y responder por la institución. Hay una obligación rotunda e inexorable que es la conducta de la institución respecto de la violencia que se crea y se exhibe en sus espacios. Eso lo estamos trabajando en la Universidad Nacional de Quilmes con el Protocolo (ver video). Son grandes escalones a subir, y lo que hace falta es la prevención, prevención y prevención y debemos estar trabajando aunque excede la propia Institución CONICET. Debería ser una matriz del Estado en todo el Sistema Educativo.

Para ver video alusivo al protocolo click aquí

Bilbao: Dentro de los marcos del protocolo, ¿cuáles son los casos en los que se detecta que hay violencia? ¿Cuáles son los tipos de violencia?

Barrancos: De todo el espectro que te puedas imaginar. Desde el acoso laboral, los casos más contingentes del acoso sexual, hasta agresiones físicas diversas y situaciones gravísimas, por ejemplo como ocurrió en el CONICET: un caso que parece de violencia doméstica pero que refiere a la institución porque ambos trabajan en la misma unidad. Hubo dos intentos de femicidio en este ejemplo que te menciono. El sujeto agresor ha estado detenido con régimen de exclusión. Todas las exclusiones son bastantes patéticas; de tres meses, que no es nada. En este caso sí: la Institución debe hacer algo más. Encuadrada como está la circunstancia judicial, dos o tres intervenciones de una jueza que lo tuvo detenido, infringiendo un poco de derecho, para salvar la vida de la víctima ya que viven en un pueblo muy pequeño. Yo pedí el traslado, no por desertización, pero no puede estar trabajando en el mismo lugar de la mujer a la que violenta porque puede ser fatal. Esta es una acción que debe hacer el CONICET. Está obligado por la ley 26.485 .

Bilbao: Esto parece dar un paso en términos de evolución cultural en la ruptura de las fronteras de la esfera pública y privada respecto de los temas de violencias.

Barrancos: Exactamente. No hay nada privado que no sea público. Lo personal es político. Es inescindible de la situación laboral, ambos trabajan en el mismo Instituto del CONICET. Y no lo podemos dejar a la aventura de lo que el señor desee hacer con esa mujer. Yo creo que ya estamos cumpliendo un año de todo este conflicto que vamos 
siguiendo. Tenemos un cuerpo, una institución interna, los representantes del CONICET, gremiales y analizan diferentes cuestiones y las denuncias en torno a la violencia.

Bilbao: La violencia es trasversal a las clases sociales. A veces parece que la violencia solo ocurre en los lugares o espacios vulnerables, desprotegidos por el Estado. Sin embargo, hablamos de las instituciones del saber, y aún así hay violencia.

Barrancos: Por supuesto. La violencia genéticamente patriarcal no reconoce fronteras de clases, de lugares, de espacios. Si se puede encontrar en los sectores de menor posibilidad de socialización, en esquemas más complejos como la Escuela, la Universidad tienen mayores dificultades para penetrar e indagar estas cuestiones. Pero absolutamente no es así. Hay espacios donde está más concentrada la violencia patriarcal y no es justamente en los sectores populares. Hay concentraciones de violencia en sectores de los más pudientes y que no es visibilizada obviamente. Eso se llama "Estandarización de la focalización de la violencia por una cuestión de clase". La capacidad de horda de machos queriendo el festín eventual, se da mucho, en sectores de poder, de acumulación simbólico y material, que acumulan las fórmulas de tentación a muchachas de sectores de altísimo riesgo. Los feminicidios ocurren en todos los grupos sociales, en las clases diferentes, ningún grupo social se libera de este flagelo. Ningún grupo social concentra la violencia, las abundantes cifras de feminicidios que tenemos.

Bilbao: Pienso en las estigmatizaciones, como lo que ocurrió con Melina Romero o Ángeles Rawson, por sus clases sociales.

Barrancos: Se exacerba la culpabilidad que tiene la víctima sobre lo que sucede. A las chicas de clase media se las priva del "Algo habrá hecho", pero las mujeres de clases populares no se salvan de ese estigma mediático. Corroen nuestras neuronas y nuestras sensibilidades. Ocurrió con la famosa niña "Candela". Es una carga semiológica de clase, pero no por el origen de la violencia. Es carga semiológica porque hay que sobre indiciar a los pobres que están en situación de peligro para "nosotros", para el resto.

Bilbao: ¿Qué ocurre en los casos de denuncias falsas?

Barrancos: El protocolo está para eso. Hay que acompañar la denuncia, cierta evidencia, actuación, para eso se llama testigos. No es precipitado. La probanza de la coherencia, cuando no hay coherencia se pone en evidencia rápidamente. Pero no se puede dejar 
para dentro de un mes. Esto debe implementarse en lo pronto para que en tiempo y forma pueda tratarse la denuncia. Porque en algunos casos se puede llegar a un sumario. No es lo mismo que robarse una notebook en la calle; nos estamos poniendo de acuerdo con los letrados y viendo qué sintonías normativas responde a esto. Cómo se actúa si hay una fragua de algo que no corresponde, de algo que puede ser delictivo para profesores y administrativos. Hay instrumentos normativos diferentes respecto de los estudiantes, por ejemplo. Esa normativa se traduce en lo que responde al Protocolo en la Universidad. Para eso está el proceso.

Bilbao: ¿El protocolo integra a todos los sujetos que forman parte de la Universidad?

Barrancos: Si, a todxs. Absolutamente a todxs. Aunque la vinculación sea provisoria o contractual.

Bilbao: ¿Cuáles son los alcances y limitaciones de este Protocolo?

Barrancos: El alcance depende de la sustentabilidad imaginaria que acompaña. Es cierto que después de un Protocolo sea difícil cajonear una serie de procedimientos de este tipo. Toma un estado de cuestión pública. No tenemos expectativas de reducción extraordinaria de la violencia pero sí, de reducción de la impunidad. Es muy probable que pasado algún tiempo la mera existencia de la norma haga sustantiva el derecho general de nuestra sociedad que debería estar enunciado en cualquier lugar. Es una obligación por lo menos desde los organismos públicos: la ley 26.485 , la Ley de Identidad de Género como herramienta. "Ante la violencia usted está amparado por el secreto de la denuncia" que es el mayor problema en las denuncias. Hay que dar garantías a todos, quien denuncia y quien es denunciado. La norma de procedimiento consagra que una serie de fenómenos no pueden ser permitidos y que además, no van a quedar impune. El objetivo es frenar la violencia contra las mujeres, todo lo que arrastra la cuestión femenina, la subalternancia y a todos los otros conjuntos como los de las sexualidades disidentes, respecto de la sujeción al patriarcado. El patriarcado sujeta a las mujeres y a los que no rindan bien el examen de la masculinidad patriarcal. El protocolo es una norma para actuar y defender a los sujetos como las mujeres, los disidentes, trans y también a aquellas víctimas de bullying. Centralmente es sobre la violencia contra las mujeres y a todo sujeto a violencia patriarcal. 